\title{
Sciendo
}

RURAL SUSTAINABILITY RESEARCH 43(338), 2020

ISSN - 2256-0939

(c) Latvia University of Life Sciences and Technologies, all rights reserved http://www.llu.Iv/en/

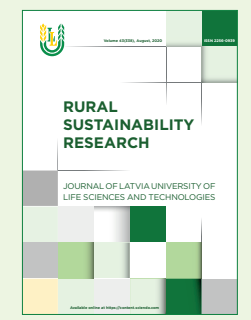

Received: 10 December 2019

Revised: 18 February 2020

Accepted: 29 May 2020

\section{Current Use of Modern Family Planning and Fertility Intention Among Women Farmers of Reproductive Age in Ido and Ona-ara Local Government Areas of Ibadan, Nigeria}

\author{
*Fausat Motunrayo Ibrahim \\ Department of Agricultural Extension and Management, \\ Federal College of Forestry, Forestry Research Institute of Nigeria, Ibadan, Oyo State, Nigeria.
}

ORCID ID: https://orcid.org/0000-0002-2264-1891

\begin{abstract}
Although poor use of contraceptives and high desire for children is characteristic of sub-Saharan Africa, this demographic challenge is more peculiar to more disadvantaged segments of the population like rural farmers. This study was designed to examine current use of modern family planning and fertility intention among women farmers of reproductive age in Ido and Ona-ara Local Government Areas of Ibadan, Nigeria. Using cross-sectional survey design, semi-structured questionnaire were administered via structured-interview to randomly and systematically selected 408 respondents. Chi-square was used to show significance of associations between pairs of variables. Contingency co-efficient was used to examine extent of significant associations. Results indicate that majority of respondents (77\%) desired additional children, the mean number of children that respondents already have is $2.94 \pm 1.35$ while mean fertility intention is $1.85 \pm 1.44$. The proportion of current users of modern family planning is $45.6 \%$. The use of oral pills $(30.6 \%)$ is most popular among respondents. There is no significant association between current use of modern family planning and fertility intention among married and divorced respondents, among respondents in all the age sub-groups, and among respondents with no formal education or secondary education $(p>0.05)$, but there is among respondents with primary and tertiary education $(p<0.05)$. The synergy between the use of modern family planning and fertility intention among women farmers in the study area is notable but requires significant progression. Having primary education and tertiary education is significantly associated respectively with lower and higher use of modern family planning in relation to fertility intention. Education is an important element of fertility dynamics among women farmers in the study area.
\end{abstract}

Keywords: Contraceptive use, fertility intention, women farmers, population growth, sub-Saharan Africa.

\section{Introduction}

Human fertility reduction is ideally a priority on the sustainable developmental agenda in developing countries. High population growth is characteristic of the forty-countries earmarked as least developed countries (United Nations, 2015), with only a few countries including Nigeria contributing significantly to world population growth. Projections indicate that between 2015-2050, only nine countries including Nigeria will contribute $50 \%$ of world population growth (United Nations, 2015). High population growth puts a lot of pressure on infrastructures.
Such growth makes it difficult for the government "to eradicate poverty and inequality, combat hunger and malnutrition, expand education enrolment and health systems, improve the provision of basic services and implement other elements of sustainable development agenda to ensure that no-one is left behind" (United Nations, 2015). Another challenge posed by increasing population growth is shortage of farmland (Headey \& Jayne, 2014), which has negative consequences on food security and human survival. High population growth is also implicated in the degradation of environmental resources like forests,

\footnotetext{
* Corresponding Author's email: fausatibrahim@gmail.com
} 
land, biodiversity, and water (Population Action International, 2010). Similarly, Yavinsky et al. (2015) asserted that population growth breeds poverty and unsustainable natural resource use particularly in rural communities. High household size has been found to be associated with the likelihood of being poor in rural Nigeria (Anyanwu, 2005).

Indeed, contraception and fertility related discourses deserve a central stage because of their centrality to population growth (Olatoregun et al. 2014; Muhammad \& Maimuna, 2014). A simulation of situations in 172 countries indicated that family planning led to the prevention of 272,040 maternal deaths in 2008. This is a $44 \%$ drop in maternal deaths that would have been recorded without contraceptive use (Ahmed et al., 2012). High-risk pregnancies including those occurring too early, too late, too closely spaced and too many underlie maternal morbidity or mortality. Contraceptive use reduces women's exposure to high-risk pregnancies and lowers the frequency of unplanned pregnancies and births (Stover \& Ross, 2010; Cleland et al., 2012). Yet, "unmet need for contraception is often highest among the most disadvantaged and vulnerable - adolescents, the poor, those living in rural areas and urban slums, people living with HIV, and internally displaced persons. These groups have the fewest resources and are the least able to deal with the demands of an unexpected pregnancy" (Starbird, Norton, \& Marcus, 2016).

Apart from unmet need for contraception, fertility intention is another challenge of population growth. Singh, Bankole and Darroch (2017) estimated the effect of contraceptive use on fertility among subSaharan Africa women of childbearing reproductive age (15-49) between 2003 and 2014. They reported that high fertility still prevails in the region and this is attributable to high unmet need for contraception among women who want to space births or who desire no more children as well as high desired fertility or fertility intention. Fertility intention is crucial to population dynamics in the light that increasing population growth is mainly a manifestation of fertility. The report of Bankole and Singh (1998) who examined fertility related issues using DHS (Demographic and Health Survey) data of 18 developing countries indicated that fertility intention (defined as intention to have another child or otherwise) is strong predictor of contraceptive behaviour. Other scholars have similarly asserted the significance of fertility intention on real fertility (Testa \& Toulemon, 2006; Islam \& Bairagi, 2003; Schoen et al. 1999; Bankole, 1995; Miller \& Pasta, 1995; Tan \& Tey, 1994).

Further, more disadvantaged segments of the population have hardly come to terms with the need for reduced fertility for optimum individual and community outcomes. In Rural Poverty Report 2011
(International Fund for Agricultural Development, 2010), it was asserted that "poverty remains largely a rural problem ... in the rural areas four out of every five households farm to some degree". Farmers are typically poorer rural residents and women farmers bear poorer fertility outcomes. The 2008, 2013 and 2018 Nigerian Demographic and Health Surveys (NDHS) shows that $6.5 \%, 5.7 \%$ and $7.2 \%$ of married women in rural Nigeria use some modern method of contraceptive respectively. When their urban counterparts are considered, these percentages increased to $16.7,16.9$ and 18.2 (National Population Commission, 2009, 2014 and 2019). Incidentally, increased population is no longer advantageous to agricultural production. A study of farming households in Kenya revealed that sustainable agricultural intensification is only practicable with low population density. An increase in this density to over 600 persons per $\mathrm{km}^{2}$ will result in reducing soil fertility (Willy, Muyanga, \& Jayne, 2019). Other scholars have asserted the detrimental trend of increased human population on sustainable agricultural production (Binswanger \& Pingali,1998; Pingali, 2012; Douwe van der Ploeg, 2012). Hence, this study was designed to examine current use of modern family planning and fertility intention among women farmers of reproductive age in Ido and Onaara LGAs Ibadan, Nigeria.

\section{Methods}

The design of this study was a cross-sectional survey targeting women farmers of reproductive age in Ido and Ona-ara LGAs Ibadan, Nigeria. Issues of fertility and contraceptive use are more relevant to women of reproductive age. Ido and Ona-ara LGAs are among the six rural of the eleven LGAs of Ibadan. The six LGAs include Akinyele, Lagelu, Egbeda, Oluyole, Ido and Ona-ara. The people of these six LGAs constituted the study population. Ibadan is a very vast community and Oyo state capital in southwestern Nigeria. Ibadan is a town of the Yorùbá ethnic group in Nigeria but other ethnic nationalities reside in the town.

Sampling procedure was multi-staged, random and systematic. According to the 2006 population census, women of the six rural LGAs in Ibadan were 608, 247 (National Population Commission, 2007). Using this total population $(\mathrm{N})$, the required sample size at $95 \%$ confidence level and confidence interval of 4.9 was 400. This was increased to 408. Two of the six LGA were randomly selected, including Ido and Ona-ara. These LGAs have a land mass of $800 \mathrm{~km}^{2}$ and 290 $\mathrm{km}^{2}$ and comprise ten and eleven political wards respectively. These wards comprise many towns and villages. The people practice agriculture extensively, growing food crops like maize, yams and potatoes. In 
each LGA, four wards were randomly selected and two villages were randomly selected from each of them. The selected villages in Ido LGA were Akufo, Abegunrin, Elenusonso, Oganla, Ido, Onikede, OmiAdio and Bakatari. On the other hand, Badeku, Jago, Ojoku, Adewumi, Gbedun, Araromi, Akanran and Ojebode villages were randomly selected in Ona-ara LGA. Using systematic sampling technique, twentysix and twenty-five respondents were selected in each of the eight villages at Ido and Ona-ara LGAs.

Data collection was through the use of semistructured questionnaire. These were administered via structured interview. The questionnaire was translated into Yorùbá language to enable communication with respondents who do not speak English language. The essence of the study was explained to each prospective respondent and their anonymity was guaranteed. Respondents were told that they were not obliged to answer to any question they do not want to, and they signified their informed consent by appending their signature. Data collection was between February and May, 2019. Response rate was 100\%.

Definitions and Assessment of Variables

Fertility status was defined as the number of biological children that respondents currently have. Respondents were simply asked to state this number of children. Desire for additional children was respondent's wish concerning having another child or children. It was nominally assessed with a single item requiring respondents to be affirmative or otherwise. Fertility intention was the number of children that respondents who wanted additional children would like to have. Respondents were simply asked to state this number. Current use of modern family planning was defined as present use of modern contraceptive as a measure of birth control. This was also nominally assessed with a single item requiring respondents to be affirmative or otherwise. Information on marital status, age and education were collected nominally. Study hypotheses

The general null hypotheses tested are as follows:

1. Ho: There is no significant association between fertility status and desire for additional children as well as fertility intention.

2. Ho: There is no significant association between current use of modern family planning and fertility intention.

3. Ho: There is no significant association between current use of modern family planning and fertility intention among respondents in different sub-groups of marital status, age and educational achievement.

\section{Data Analyses}

Frequency counts and percentages were used to examine distribution of data. Cross-tabulation and chi-square were used to show distributions and significance of associations between pairs of variables respectively. Further, these distributions and associations were disaggregated by marital status, age and education; using cross-tabs. Where significant associations were recorded, contingency coefficient was used to examine extent of the association. Data analyses were conducted using Statistical Package for Social Sciences (version 21).

\section{Results and Discussions}

Socio-demographic Characteristics of Respondents

Most respondents were married $(90.7 \%)$ while minorities $(3.2 \%$ and $4.9 \%)$ were divorced and widowed respectively. Two respondents were single. The distribution of marital status is an indication of marriage stability among respondents in the study area. Almost one out of every two respondents (49\%) was a secondary school certificate holder. More than a quarter $(26.5 \%)$ held primary school certificates while up to one of every five (18.9\%) had no formal education. Few respondents $(3.6 \%)$ had tertiary education. The percentage of respondents who have never attended formal schooling is quite high. Most respondents (40.2\%) were aged between 29 and 35 years. All age sub-groups were well represented in the study. Majority (53.7\%) of respondents practice Christianity while Muslims were $41.1 \%$. A small percentage (4.9) of respondents were traditional religion practitioners. This signifies some survival of traditional religion among women in the study area. In line with expectation, most respondents (81.4\%) were Yorùbá. Other ethnic groups were also represented in the study. The distribution of socio-demographic characteristics of respondents is presented in Table 1. Fertility Issues Among Respondents

Table 2 shows that the mean number of children that respondents have is $2.94 \pm 1.35$. Most respondents (30.1\%) have three children and $28.4 \%$ have two children while $16.9 \%$ have four children. No respondents have more than seven children. This distribution still very much resembles the high fertility character of sub-Saharan Africa. This is more so because respondents are still within their reproductive years and most of them (77\%) are still expected to have more. Table 2 further shows that the majority of respondents $(77 \%)$ gave affirmative response to the question probing their desire for additional children. Three respondents did not respond to this question while $22.3 \%$ do not desire to have children again. In addition, Table 2 indicates that the mean fertility intention was $1.85 \pm 1.44$. About one-fifth of respondents do not want additional children. Most respondents wanted one additional child (23.0\%) or two children (23.8\%). Fertility status, desire for additional 
Socio-demographic characteristics of respondents $(N=408)$

\begin{tabular}{|c|c|c|c|}
\hline $\begin{array}{c}\text { Socio-demographic } \\
\text { characteristics }\end{array}$ & Sub-groups & Frequency & $\begin{array}{c}\text { Percentage } \\
(\%)\end{array}$ \\
\hline \multirow[t]{5}{*}{ Marital status } & Single & 2 & 0.5 \\
\hline & Married & 370 & 90.7 \\
\hline & Divorced & 13 & 3.2 \\
\hline & Widowed & 20 & 4.9 \\
\hline & No response & 3 & 0.7 \\
\hline \multirow[t]{6}{*}{ Education* } & No formal education & 77 & 18.9 \\
\hline & Primary school certificate & 108 & 26.5 \\
\hline & Secondary school certificate & 200 & 49.0 \\
\hline & NCE/OND/HSC/A LEVEL & 14 & 3.4 \\
\hline & $\mathrm{BSC} / \mathrm{HND}$ & 1 & 0.2 \\
\hline & No response & 8 & 2.0 \\
\hline \multirow[t]{5}{*}{ Age** } & $15-21$ & 14 & 3.4 \\
\hline & $22-28$ & 100 & 24.5 \\
\hline & $29-35$ & 164 & 40.2 \\
\hline & $36-42$ & 91 & 22.3 \\
\hline & $43-49$ & 39 & 9.6 \\
\hline \multirow[t]{3}{*}{ Religion } & Islam & 169 & 41.1 \\
\hline & Christianity & 219 & 53.7 \\
\hline & Traditional & 20 & 4.9 \\
\hline \multirow[t]{7}{*}{ Ethnicity } & Yorùbá & 332 & 81.4 \\
\hline & Igede & 33 & 8.1 \\
\hline & Igbo & 25 & 6.1 \\
\hline & Hausa & 9 & 2.2 \\
\hline & Cotonou & 5 & 1.2 \\
\hline & Isoko & 2 & 0.5 \\
\hline & No response & 2 & 0.5 \\
\hline
\end{tabular}

$* N C E=$ National Certificate in Education, OND = Ordinary National Diploma, HSC = Higher School Certificate, A $L E V E L=$ Advanced Level Certificate, $B S c=$ Bachelor of Science, $H N D=$ Higher National Diploma

$* *$ The mean age was $32.88 \pm 6.79$, minimum $=20$, maximum $=49$

children and fertility intention among respondents showcases high demand for children, contrary to global fertility dynamics. However, lowered demand for children is beneficial for economic well-being and otherwise. For instance, Korotayev, Zinkina, Goldstone and Shulgin (2016) asserted that "almost all the countries of Asia are successfully completing their fertility transition or have already completed it, and their promptness in fertility decline seems to have played a great role in their economic achievements and in Asian development as a whole". Respondents in this study $(54.4 \%)$ were not utilizing family planning as at the time of the survey but $45.6 \%$ were using some. This proportion of modern contraceptive users is far greater than what is in larger Nigerian society. The Nigerian 2018 Demographic and Health Survey shows that $7.2 \%$ and $18.2 \%$ of married women in rural and urban Nigeria respectively use any modern method of contraceptive (National Population Commission, 2019). Hence, contraceptive behaviour among women farmers in the study area is friendlier to fertility change when compared with this behavior in the larger Nigerian women populace.

Types of Family Planning Method Used Among Respondents

Table 3 shows that the use of oral pills $(30.6 \%)$ is most popular among respondents. Female and male condom use were practiced by $3.9 \%$ and $8.1 \%$ of respondents respectively, thus indicating the greater popularity of male rather than female condom use among women farmers in the study area. Male condom use is next to the most popular, and this was followed by hormonal injection $(7.4 \%)$. Implants $(6.8 \%)$ and intra-uterine device (6.4\%) are also used among respondents. This distribution generally contradicts the position of Darroch and Singh (2013) 
who reported that injectables and implants, followed by the pill and condoms were the most popular modern contraceptive methods in sub-Saharan Africa. Similarly, current findings also contradict the result of 2018 NDHS which showed that the most popular methods were implants, injectables, and withdrawal (among currently married women). These were each used by $3 \%$ while male condoms were used by $2 \%$ of respondents. This presupposes that the target population is quite different from Nigerian women population.

Fertility Status and Desire for Additional Children

The crosstab on Table 4 shows that the desire to have children as well as additional children is overwhelmingly high among respondents who do not have children and those who already have 1 to 3 children. Among those who have four children, $61.8 \%$ still wanted additional children. The percentage of those desiring additional children only dropped sharply to $32 \%$ among those who have had five children. These data showcase high demand for children and unpopularity of replacement fertility among women farmers in the study area. The chisquare value is $163.390(p<0.05)$. Hence, there is a significant association between fertility status and desire for additional children. The null hypothesis is rejected. This finding is intuitive. The contingency coefficient $(0.536)$ indicates that the extent of this association is $53.6 \%$.

Fertility Status and Fertility Intention Among Respondents

The cross-tab on Table 5 shows that the few respondents who have not had children want to have four children. Most (44.9\%) of those who have one child desire to have additional three children while $28.6 \%$ desire additional four children. Only $18.2 \%$, $35.3 \%, 68 \%$ and $94.7 \%$ of those who already have three, four, five and six children respectively do not desire to have children any more. Fertility intention responds to fertility status, and it also showcases high demand for children among women farmers in the study area. The chi-square value is 231.684

Table 2

Distribution of fertility issues among respondents $(N=408)$

\begin{tabular}{|c|c|c|c|}
\hline & & Frequency & Percentage \\
\hline \multirow[t]{8}{*}{ Fertility status* } & 0 & 2 & 0.5 \\
\hline & 1 & 49 & 12.0 \\
\hline & 2 & 116 & 28.4 \\
\hline & 3 & 123 & 30.1 \\
\hline & 4 & 69 & 16.9 \\
\hline & 5 & 25 & 6.1 \\
\hline & 6 & 19 & 4.7 \\
\hline & 7 & 5 & 1.2 \\
\hline \multirow[t]{3}{*}{ Desire for additional children } & $\mathrm{NO}$ & 91 & 22.3 \\
\hline & YES & 314 & 77.0 \\
\hline & No response & 3 & 0.7 \\
\hline \multirow[t]{8}{*}{ Fertility intention $* *$} & 0 & 87 & 21.3 \\
\hline & 1 & 94 & 23.0 \\
\hline & 2 & 97 & 23.8 \\
\hline & 3 & 61 & 15.0 \\
\hline & 4 & 50 & 12.3 \\
\hline & 5 & 13 & 3.2 \\
\hline & 6 & 2 & 0.5 \\
\hline & No response & 4 & 1.0 \\
\hline \multirow[t]{2}{*}{ Current use of modern family planning } & Yes (Users) & 183 & 45.6 \\
\hline & No (Non-users) & 220 & 54.4 \\
\hline
\end{tabular}

*Mean fertility status $=2.94 \pm 1.35$

$* *$ Mean fertility intention $=1.85 \pm 1.44$ 
Types of family planning method used among respondents

\begin{tabular}{|l|l|c|c|c|}
\hline \multicolumn{1}{|c|}{ Type } & \multicolumn{1}{|c|}{ Item } & YES (\%) & NO (\%) & No response (\%) \\
\hline \multirow{3}{*}{$\begin{array}{l}\text { Traditional } \\
\text { methods }\end{array}$} & Withdrawal method & 6.9 & 91.9 & 1.2 \\
\cline { 2 - 5 } & Safe period (rhythm) & 4.2 & 94.9 & 0.9 \\
\cline { 2 - 5 } & Folk method (charms, rings) & 4.7 & 93.6 & 1.7 \\
\hline \multirow{4}{*}{ Modern methods } & Oral pills & 30.6 & 67.6 & 1.8 \\
\cline { 2 - 5 } & Intrauterine device (IUD) & 6.4 & 92.6 & 1.0 \\
\cline { 2 - 5 } & Hormonal injection & 7.4 & 91.9 & 0.7 \\
\cline { 2 - 5 } & Implants & 6.8 & 92.2 & 1.0 \\
\cline { 2 - 5 } & Female condom & 3.9 & 95.3 & 0.7 \\
\cline { 2 - 5 } & Male condom & 8.1 & 90.9 & 1.0 \\
\hline
\end{tabular}

Table 4

\section{Cross-tabulation of fertility status and desire for additional children}

\begin{tabular}{|c|c|c|}
\hline \multirow{2}{*}{ Fertility status } & \multicolumn{2}{|c|}{ Desire for additional children } \\
\cline { 2 - 3 } & NO (\%) & YES (\%) \\
\hline 0 & 0 & 100 \\
\hline 1 & 2 & 98 \\
\hline 2 & 0 & 100 \\
\hline 3 & 18.9 & 61.1 \\
\hline 4 & 38.2 & 32.0 \\
\hline 5 & 68.0 & 5.3 \\
\hline 6 & 94.7 & 0 \\
\hline 7 & 100 & \\
\hline
\end{tabular}

Chi-square $=163.390, d f=7, p=0.000 ;$ Contingency co-efficient $=0.536,(p=0.000)$

$(p<0.05)$, making it conclusive that there is significant association between fertility status and fertility intention. The null hypothesis is rejected. This finding is also intuitive. The contingency co-efficient (0.604) shows that the extent of this association is $60.4 \%$. Current Use of Modern Family Planning and Fertility Intention Among Respondents

The interplay between fertility intention and current use of modern family is represented on Table 6. The table shows that $0.5 \%, 3.2 \%$ and $14.3 \%$ of those who wanted additional six, five and four children respectively are non-users. Those who wanted no additional children $(27.6 \%)$, one additional child (16.6) and two additional children (23\%) were also not currently using modern family planning. One would expect those not desiring additional children to be users of modern family planning. Incidentally, this appears not to be largely so. Table 6 also shows that
$14 \%, 30.8 \%$ and $25.3 \%$ of users desired no more, one and two additional children respectively. Considering distribution with fertility intention, $69.8 \%$ of those not desiring additional children were non-users. This is also similar to the distribution of those desiring four children, where $62 \%$ were non-users. The chisquare value is $18.250(p<0.05)$. Hence, there is a significant association between current use of modern family planning and fertility intention. The null hypothesis is rejected. The contingency coefficient $(0.209)$ shows that the extent of this association is $20.9 \%$. This is rather low and indicates poor, unideal synergy between the use of modern family planning and fertility intention among women farmers in the study area. Hence, this finding populates assertions implicating unmet need for family planning on high fertility in sub-Saharan Africa (Singh, Bankole \& Darroch, 2017). 
Socio-demographic Breakdown of Current Use of Modern Family Planning and Fertility Intention

Marital Status, Current Use of Modern Family Planning and Fertility Intention

Ho: There is no significant association between the current use of modern family planning and fertility intention among single, married, divorced and widowed respondents.

Table 7 is a breakdown of current use of modern family planning and fertility intention by marital status. Those who desired additional four children and were single were also non-users of modern family planning. Table 7 also shows that among married respondents desiring no additional children, $60.7 \%$ of them were non-users. This distribution is similar to those desiring additional four children, where $61.7 \%$ of married respondents were also non-users. This distribution is even higher than the one reported by Singh and Darroch (2012) who estimated that 30-37\% of married women in West Africa have unmet need to use modern contraceptives. The chi-square of these distributions among married respondents alone was 9.457 $(p>0.05)$. Hence, there is no significant association between current use of modern family planning and fertility intention among married respondents. Majority (66.7\%) of divorced respondents desiring no additional children were non-users. This is very similar to findings among married respondents. However, there were generally more users among divorced respondents $(61.5 \%)$ than among married respondents $(47.8 \%)$. There was also no significant association between current use of modern family planning and fertility intention among divorced respondents $(p>0.05)$. The null hypothesis is accepted. All widowed respondents desired no additional children and were non-users. This is intuitive.

Age, Current Use of Modern Family Planning and Fertility Intention

There is no significant association between current use of modern family planning and fertility intention among respondents aged between 15-21, 22-28, 29 $35,36-42$ and $43-49$.

Table 8 is a presentation of the breakdown of current use of modern family planning and fertility intention by age. Among those aged between 15-21, 22-28, 29$35,36-42$ and $43-49$, users were $53.8 \%, 37.4 \%, 54.7 \%$, $40.2 \%$ and $38.5 \%$ respectively. The $15-21$ and $29-35$ age sub-groups were those above total users which

\section{Cross-tabulation of fertility status and fertility intention among respondents}

Table 5

\begin{tabular}{|c|c|c|c|c|c|c|c|}
\hline \multirow{2}{*}{ Fertility status } & \multicolumn{7}{|c|}{ Desired number of children } \\
\cline { 2 - 8 } & $0(\%)$ & $1(\%)$ & $2(\%)$ & $3(\%)$ & $4(\%)$ & $5(\%)$ & $6(\%)$ \\
\hline 0 & 0 & 0 & 0 & 0 & 100 & 0 & 0 \\
\hline 1 & 0 & 4.1 & 18.4 & 44.9 & 28.6 & 4.1 & 0 \\
\hline 2 & 0 & 31.9 & 26.7 & 19.0 & 16.4 & 5.2 & 0.9 \\
\hline 3 & 18.2 & 30.6 & 28.9 & 7.4 & 10.7 & 4.1 & 0 \\
\hline 4 & 35.3 & 20.6 & 27.9 & 8.8 & 5.9 & 0.0 & 1.5 \\
\hline 5 & 68.0 & 12.0 & 12.0 & 8.0 & 0 & 0 & 0 \\
\hline 6 & 94.7 & 5.3 & 0 & 0 & 0 & 0 & 0 \\
\hline 7 & 100 & 0 & 0 & 0 & 0 & 0 & 0 \\
\hline
\end{tabular}

Chi-square $=231.684, d f=42, p=0.000 ;$ Contingency co-efficient $=0.604,(p=0.000)$

\section{Cross-tabulation of current use of modern family planning and fertility intention among respondents}

Table 6

\begin{tabular}{|l|l|c|c|c|c|c|c|c|c|}
\hline \multirow{2}{*}{ C-use } & \multicolumn{1}{|c|}{ Count } & \multicolumn{6}{|c|}{ Fertility intention (desired number of additional children, \%) } \\
\cline { 2 - 10 } & & 0 & 1 & 2 & 3 & 4 & 5 & 6 & Total \\
\hline \multirow{3}{*}{ Non-users } & \% within c-use & 27.6 & 16.6 & 23.0 & 14.7 & 14.3 & 3.2 & 0.5 & 100 \\
\cline { 2 - 11 } & \% within f- intention & 69.8 & 39.1 & 52.1 & 53.3 & 62.0 & 53.8 & 50.0 & 54.4 \\
\hline \multirow{3}{*}{ Users } & \% within c-use & 14.0 & 30.8 & 25.3 & 15.4 & 10.4 & 3.3 & 0.5 & 100 \\
\cline { 2 - 10 } & \% within f-intention & 30.2 & 60.9 & 47.9 & 46.7 & 38.0 & 46.2 & 50.0 & 45.6 \\
\cline { 2 - 10 } & Total & 100 & 100 & 100 & 100 & 100 & 100 & 100 & 100 \\
\hline
\end{tabular}

Chi-square $=18.250, d f=6, p=0.006 ;$ Contingency co-efficient $=0.209,(p=0.006)$ 
Current use of modern family planning and fertility intention disaggregated by marital status

Table 7

\begin{tabular}{|c|c|c|c|c|c|c|c|c|c|}
\hline \multirow{2}{*}{$\begin{array}{l}\text { Marital } \\
\text { Status }\end{array}$} & \multirow{2}{*}{$\begin{array}{l}\text { Current use of FP } \\
\text { status } \\
\text { (C-Use) }\end{array}$} & \multicolumn{7}{|c|}{ Fertility intention (desired number of additional children, $\%$ ) } & \multirow[b]{2}{*}{ Total } \\
\hline & & 0 & 1 & 2 & 3 & 4 & 5 & 6 & \\
\hline \multirow[t]{2}{*}{ Single $^{a}$} & Non-users $(\%)$ & - & - & - & - & 100 & - & - & - \\
\hline & Total & - & - & - & - & 100 & - & - & - \\
\hline \multirow[t]{3}{*}{ Married $^{\mathrm{b}}$} & Non-users $(\%)$ & 60.7 & 39.3 & 53.3 & 53.4 & 61.7 & 53.8 & 50.0 & 52.2 \\
\hline & Users $(\%)$ & 39.3 & 60.7 & 46.7 & 46.6 & 38.3 & 46.2 & 50.0 & 47.8 \\
\hline & Total & 100.0 & 100.0 & 100.0 & 100.0 & 100.0 & 100.0 & 100.0 & 100.0 \\
\hline \multirow[t]{3}{*}{ Divorced $^{c}$} & Non-users $(\%)$ & 66.7 & 0.0 & 25.0 & 0.0 & - & - & - & 38.5 \\
\hline & Users $(\%)$ & 33.3 & 100.0 & 75.0 & 100.0 & - & - & - & 61.5 \\
\hline & Total & 100.0 & 100.0 & 100.0 & 100.0 & - & - & - & 100.0 \\
\hline \multirow[t]{2}{*}{ Widowed $^{\mathrm{d}}$} & Non-users $(\%)$ & 100.0 & - & - & - & - & - & - & - \\
\hline & Total & 100.0 & - & - & - & - & - & - & - \\
\hline \multirow[t]{3}{*}{ Total $^{\mathrm{e}}$} & Total non-users $(\%)$ & 69.8 & 38.5 & 52.1 & 52.5 & 63.3 & 53.8 & 50.0 & 54.3 \\
\hline & Total users $(\%)$ & 30.2 & 61.5 & 47.9 & 47.5 & 36.7 & 46.2 & 50.0 & 45.7 \\
\hline & Overall total & 100.0 & 100.0 & 100.0 & 100.0 & 100.0 & 100. & 100.0 & 100.0 \\
\hline
\end{tabular}

${ }^{a}$ Chi-square not computed because $C$-Use and fertility intention are constant

${ }^{b}$ Chi-square $=9.457, d f=6, p=0.149 ;$ Contingency co-efficient $=0.160,(p=0.149)$

${ }^{c}$ Chi-square $=4.198, d f=3, p=0.241$; Contingency co-efficient $=0.494,(p=0.241)$

${ }^{d}$ Chi-square not computed because $C$-Use and fertility intention are constant

${ }^{e}$ Chi-square $=19.357, d f=6, p=0.004 ;$ Contingency co-efficient $=0.216,(p=0.004)$

Table 8

Fertility intention and current use of modern family planning disaggregated by age

\begin{tabular}{|c|c|c|c|c|c|c|c|c|c|}
\hline \multirow[b]{2}{*}{ Age } & \multirow{2}{*}{$\begin{array}{c}\text { Current use of FP } \\
\text { status } \\
\text { (C-Use })\end{array}$} & \multicolumn{7}{|c|}{ Fertility intention (desired number of additional children, \%) } & \multirow[b]{2}{*}{ Total } \\
\hline & & 0 & 1 & 2 & 3 & 4 & 5 & 6 & \\
\hline \multirow[t]{3}{*}{$15-21^{\mathrm{a}}$} & Non-users $(\%)$ & - & 50.0 & 33.3 & - & 40.0 & 66.7 & - & 46.2 \\
\hline & Users $(\%)$ & - & 50.0 & 66.7 & - & 60.0 & 33.3 & - & 53.8 \\
\hline & Total & - & 100 & 100 & - & 100 & 100 & - & 100 \\
\hline \multirow[t]{3}{*}{$22-28^{b}$} & Non-users $(\%)$ & 83.3 & 45.5 & 70.8 & 52.2 & 67.9 & 66.7 & 0.0 & 62.6 \\
\hline & Users $(\%)$ & 16.7 & 54.5 & 29. & 47.8 & 32.1 & 33.3 & 100.0 & 37.4 \\
\hline & Total & 100 & 100 & 100 & 100 & 100 & 100 & 100 & 100 \\
\hline \multirow[t]{3}{*}{$29-35^{\mathrm{c}}$} & Non-users (\%) & 50.0 & 36.0 & 44.7 & 51.6 & 64.3 & 25.0 & 100.0 & 45.3 \\
\hline & Users $(\%)$ & 50.0 & 64.0 & 55.3 & 48.4 & 35.7 & 75.0 & 0.0 & 54.7 \\
\hline & Total & 100 & 100 & 100 & 100 & 100 & 100 & 100 & 100 \\
\hline \multirow[t]{3}{*}{$36-42^{\mathrm{d}}$} & Non-users (\%) & 78.8 & 44.0 & 50.0 & 66.7 & 33.3 & - & - & 59.8 \\
\hline & Users (\%) & 21.2 & 56.0 & 50.0 & 33.3 & 66.7 & - & - & 40.2 \\
\hline & Total & 100 & 100 & 100 & 100 & 100 & - & - & 100 \\
\hline \multirow[t]{3}{*}{$43-49^{e}$} & Non-users $(\%)$ & 66.7 & 25.0 & 50.0 & - & - & - & - & 61.5 \\
\hline & Users $(\%)$ & 33.3 & 75.0 & 50.0 & - & - & - & - & 38.5 \\
\hline & Total & 100 & 100 & 100 & - & - & - & - & 100 \\
\hline \multirow[t]{3}{*}{ Total $^{\mathrm{f}}$} & Total non-users (\%) & 69.8 & 39.1 & 52.1 & 53.3 & 62.0 & 53.8 & 50.0 & 54.4 \\
\hline & Total users $(\%)$ & 30.2 & 60.9 & 47.9 & 46. & 38.0 & 46.2 & 50.0 & 45.6 \\
\hline & Overall total (\%) & 100 & 100 & 100 & 100 & 100 & 100 & 100 & 100 \\
\hline
\end{tabular}

${ }^{a}$ Chi-square $=.794, d f=3, p=0.851 ;$ Contingency co-efficient $=0.240,(p=0.851)$

${ }^{b}$ Chi-square $=6.294, d f=6, p=0.391 ;$ Contingency co-efficient $=0.244,(p=0.391)$

${ }^{c}$ Chi-square $=6.284, d f=6, p=0.392 ;$ Contingency co-efficient $=0.194,(p=0.392)$

${ }^{d}$ Chi-square $=9.334, d f=4, p=0.053 ;$ Contingency co-efficient $=0.311,(p=0.053)$

${ }^{e}$ Chi-square $=2.735, d f=2, p=0.255 ;$ Contingency co-efficient $=0.256,(p=0.255)$

${ }^{f}$ Chi-square $=18.250, d f=6, p=0.006 ;$ Contingency co-efficient $=0.209,(p=0.006)$ 
Fertility intention and current use of modern family planning disaggregated by education

\begin{tabular}{|c|c|c|c|c|c|c|c|c|c|}
\hline \multirow{2}{*}{$\begin{array}{l}\text { Educational } \\
\text { qualification }\end{array}$} & \multirow{2}{*}{$\begin{array}{c}\text { Current use of FP } \\
\text { status } \\
\text { (C-Use) }\end{array}$} & \multicolumn{7}{|c|}{ Fertility intention (desired number of additional children, \%) } & \multirow[b]{2}{*}{ Total } \\
\hline & & 0 & 1 & 2 & 3 & 4 & 5 & 6 & \\
\hline \multirow{3}{*}{$\begin{array}{l}\text { No formal } \\
\text { education }{ }^{\text {a }}\end{array}$} & Non-users $(\%)$ & 70.6 & 33.3 & 75.0 & 84.6 & 78.9 & 83.3 & 50.0 & 75.0 \\
\hline & Users $(\%)$ & 29.4 & 66.7 & 25.0 & 15.4 & 21.1 & 16.7 & 50.0 & 25.0 \\
\hline & Total & 100 & 100 & 100 & 100 & 100 & 100 & 100 & 100 \\
\hline \multirow{3}{*}{$\begin{array}{l}\text { Pry school } \\
\text { certificate }^{\text {b }}\end{array}$} & Non-users $(\%)$ & 85.7 & 47.8 & 57.7 & 55.6 & 72.7 & 50.0 & - & 66.0 \\
\hline & Users $(\%)$ & 14.3 & 52.2 & 42.3 & 44.4 & 27.3 & 50.0 & - & 34.0 \\
\hline & Total & 100 & 100 & 100 & 100 & 100 & 100 & - & 100 \\
\hline \multirow{3}{*}{$\begin{array}{l}\text { Secondary } \\
\text { school }^{\mathrm{c}}\end{array}$} & Non-users $(\%)$ & 56.3 & 33.3 & 44.9 & 37.1 & 35.3 & 0.0 & - & 40.2 \\
\hline & Users $(\%)$ & 43.8 & 66.7 & 55.1 & 62.9 & 64.7 & 100.0 & - & 59.8 \\
\hline & Total & 100 & 100 & 100 & 100 & 100 & 100 & - & 100 \\
\hline \multirow[t]{3}{*}{ Tertiary $^{\mathrm{d}}$} & Non-users (\%) & 0.0 & 57.1 & 0.0 & 100.0 & - & - & - & 42.9 \\
\hline & Users (\%) & 100.0 & 42.9 & 100.0 & $0.0 \%$ & - & - & - & 57.1 \\
\hline & Total & 100.0 & 100.0 & 100.0 & 100 & - & - & - & 100.0 \\
\hline \multirow[t]{3}{*}{ Total $^{\mathrm{e}}$} & Total non-users $(\%)$ & 69.8 & 38.5 & 52.1 & 52.5 & 61.7 & 50.0 & 50.0 & 54.0 \\
\hline & Total users $(\%)$ & 30.2 & 61.5 & 47.9 & 47.5 & 38.3 & 50.0 & 50.0 & 46.0 \\
\hline & Overall total & 100 & 100 & 100 & 100 & 100 & 100 & 100 & 100 \\
\hline
\end{tabular}

${ }^{a}$ Chi-square $=4.642, d f=6, p=0.590 ;$ Contingency co-efficient $=0.240,(p=0.590)$

${ }^{b}$ Chi-square $=11.140, d f=5, p=0.049 ;$ Contingency co-efficient $=0.308,(p=0.049)$

${ }^{c}$ Chi-square $=7.992, d f=5, p=0.157 ;$ Contingency co-efficient $=0.199,(p=0.157)$

${ }^{d}$ Chi-square $=7.000, d f=3, p=0.042 ;$ Contingency co-efficient $=0.577,(p=0.042)$

${ }^{e}$ Chi-square $=18.846, d f=6, p=0.004 ;$ Contingency co-efficient $=0.214,(p=0.004)$

were $45.6 \%$. The 2018 NDHS indicated that modern contraceptive use reached a peak of $23 \%$ among women age 35-39 (National Population Commission, 2019). In this study, current use of modern family planning reached a peak of $54.7 \%$ among women aged 29 to 35 . This indicates that the peak use of modern contraceptives among women farmers in the study area occurs among relatively younger women when compared with the peak use in general Nigerian women population. Among those wanting no additional children, $83.3 \%$ of those aged $22-28$ were non-users. This percentage was $78.8 \%$ among those aged between 36 to 42 . There is no significant association between current use of modern family planning and fertility intention in all the age sub-groups $(p>0.05)$. Age is not a significant factor in current use of modern family planning and fertility intention.

Education, Current Use of Modern Family Planning and Fertility Intention

Ho: There is no significant association between current use of modern family planning and fertility intention among respondents with no formal education, primary education, secondary education and tertiary education.
Table 9 shows a breakdown of current use of modern family planning and fertility intention by education. Among those without formal education, total users were $25 \%$. This percentage increased to $34 \%$ among those with primary school certificate and further increased to $59.8 \%$ among secondary school certificate holders. However, this percentage reduced slightly to $57.1 \%$ among those with tertiary education.

Among those without formal education, 70.6\% of those not desiring additional children were nonusers. This percentage increased to $85.7 \%$ among primary school certificate holders but reduced sharply to $56.3 \%$ among secondary school certificate holders. More interestingly, all respondents with tertiary education desiring no more children were users of modern contraceptive. There was no significant association between current use of modern family planning and fertility intention among those without formal education and those with secondary education $(p>0.05)$. However, there was significant association between current use of modern family planning and fertility intention among respondents with primary education and those with tertiary education. The null 
hypotheses are rejected. Primary education and tertiary education are significantly associated with lower and higher use of modern family planning in relation to fertility intention respectively. This underscores the growing agreement that increasing education is important in determining contraceptive use in subSaharan Africa (Bongaarts and Hardee, 2018; Ajibola, Jacob and Omotosho, 2018; Alaba, Olubusoye and Olaomi, 2017 and Wusu and Isiugo-Abanihe, 2019). Contingency coefficients indicate that the extent of the association between current use of modern family planning and fertility intention among primary school certificate holders and tertiary education achievers is $30.8 \%$ and $57.7 \%$ respectively.

\section{Conclusions}

Current use of modern family planning, fertility intention, fertility status among majority of respondents still very much resembles the high fertility character of sub-Saharan Africa. These variables have underscored the 'African effect' as the main issue in high fertility of sub-Saharan Africa. The African effect is greater desire for children and poor use of contraceptives. The variables also showcase the unpopularity of replacement fertility among women farmers in the study area. Yet, fertility decline is prime in accelerating economic wherewithal at the household, community and national levels. However, the proportion of modern contraceptive users is far greater than what obtains in larger Nigerian society making contraceptive behaviour among women farmers in the study area to be friendlier to fertility change when compared with this behavior in the larger Nigerian women populace.

The significant association between current use of modern family planning and fertility intention is weak and therefore underscores the unideal synergy between the use of modern family planning and fertility intention among women farmers in the study area. Being married or divorced is insignificantly associated with current use of modern family planning and fertility intention. Age is not a significant factor in current use of modern family planning and fertility intention. Having no formal education or secondary education is also insignificantly associated with current use of modern family planning and fertility intention. However, having primary education and/ or tertiary education is significantly associated respectively with lower and higher use of modern family planning in relation to fertility intention. This underscores the growing agreement that increasing education is important in determining contraceptive use in sub-Saharan Africa.

\section{References}

Ahmed, S., Li, Q., Liu, L., \& Tsui, A.O. (2012). Maternal deaths averted by contraceptive use: an analysis of 172 countries. Lancet 380(9837): 111-125.

Ajibola, A., Jacob, O. A., \& Omotosho, E. (2018). Stylized Facts and Review of the Relation between Contraceptive Use, Delinquency and Age Structure in Nigeria, and It's Implications for Demographic Dividend. Open Access Library Journal, 5: e4321. DOI: https://doi.org/10.4236/ oalib. 1104321.

Alaba, O. O., Olubusoye, O. E., \& Olaomi, J. O. (2017). Spatial Patterns and Determinants of Fertility Levels Among Women of Childbearing Age in Nigeria. South African Family Practice, 59(4), 143-147.

Anyanwu, J.C. (2005). Rural poverty in Nigeria: profile, determinants and exit paths. African Development Review 17(3), 435-460.

Bankole, A. \& Singh, S. (1998). Couples' Fertility and Contraceptive Decision-making in Developing Countries: Hearing the Man's Voice. International Family Planning Perspectives, 24(1), 15-24.

Bankole, A. (1995). Desired Fertility and Fertility Behaviour Among the Yoruba of Nigeria: A Study of Couple Preferences and Subsequent Fertility. Population Studies: A Journal of Demography, 49(2), 317-328.

Binswanger, H.P., \& Pingali, P., (1998). Population density and farming systems: the changing locus of innovations and technical change. In: Lee, R.D. (Ed.), Population, Food and Rural Development. Oxford University Press, Oxford, UK.

Bongaarts, J., \& Hardee, K. (2018). Trends in Contraceptive Prevalence in Sub-Saharan Africa: The Roles of Family Planning Programs and Education. Available at SSRN 3255823. Retrieved June 27,2019 from https://www. un.org/en/development/desa/population/events/ pdf/expert/28/EGM_John_Bongaarts.pdf

Cleland, J., Conde-Agudelo, A., Peterson, H., Ross, J., \& Tsui, A. (2012). Contraception and health. Lancet 380(9837), 149-156.

Darroch, J. E., \& Singh, S. (2013). Trends in Contraceptive Need and Use in Developing Countries in 2003, 2008, and 2012: An Analysis of National Surveys. Lancet 381(9879), 1756-1762.

Douwe van der Ploeg, J. (2012). Poverty Alleviation and Smallholder Agriculture: The Rural Poverty Report 2011. Development and Change 43(1), 439-448.

Headey, D., \& Jayne, T.S. (2014). Adaptation to Land Constraints: Is Africa Different? Food Policy, 48, $18-33$. 
International Fund for Agricultural Development (2010). Rural Poverty Report 2011, Rome: International Fund for Agricultural Development Pp. 5, 47.

Islam, M.M. \& Bairagi, R. (2003). Fertility Intentions and Subsequent Fertility Behaviour In Matlab: Do Fertility Intentions Matter? Journal of Biosocial Science, 35, 615-619.

Korotayev, A., Zinkina, J., Goldstone, J. \& Shulgin, S. (2016). Explaining Current Fertility Dynamics in Tropical Africa From an Anthropological Perspective: A Cross-Cultural Investigation. Cross-Cultural Research, 50(3), 251-280.

Miller, W.B. \& Pasta, D.J. (1995). Behavioral Intentions: Which Ones Predict Fertility Behavior in Married Couples? Journal of Applied Social Psychology, 25(6), 530-555.

Muhammad, Z. \& Maimuna, D.G. (2014). Contraceptive Trend in a Tertiary Facility in North Western Nigeria: A 10-year review. Nigerian Journal of Basic and Clinical Sciences, 11(2), 99-103.

National Population Commission, (2007). 2006 National Population Census. NPC Publication, Ann Arbor, MI.

National Population Commission (NPC) [Nigeria] and ICF Macro. (2009). Nigeria Demographic and Health Survey 2008. Abuja, Nigeria: National Population Commission and ICF Macro.

National Population Commission (NPC) [Nigeria] and ICF International. (2014). Nigeria Demographic and Health Survey 2013. Abuja, Nigeria, and Rockville, Maryland, USA: NPC and ICF International.2014

National Population Commission (NPC) [Nigeria] and ICF. (2019). Nigeria Demographic and Health Survey 2018 Key Indicators Report. Abuja, Nigeria, and Rockville, Maryland, USA: NPC and ICF. International, 2019.

Olatoregun, O., Fagbamigbe, A.F., Akinyemi, O.J., Yusuf, O.B., \& Bamgboye, E.A. (2014). A Comparative Analysis of Fertility Differentials in Ghana and Nigeria. African Journal of Reproductive Health, 18(3), 36-47.

Pingali, P., (2012). Green Revolution: Impacts, Limits and the Path Ahead. Proceeding of National Academy of Science, U. S. A, 109, 12302-12308

Population Action International (PAI) (2010). Why population matters. Washington (DC): Retrieved January 20, 2019 from: http://pai.org/wp-content/ uploads/2011/10/Why-Population-Matters.pdf

Schoen, R., Astone, N.M., Kim, Y.J., Nathanson, C.A., \& Fields, J.M. (1999). Do Fertility Intentions
Affect Fertility Behavior? Journal of Marriage and Family, 61(3), 790-799.

Singh, S., \& Darroch, J. (2012). Adding it all up: The Cost and Benefits of Investing in Family PlanningEstimates for 2012. New York: Guttmacher Institute and United Nations Fund for Population Activities.

Singh, S., Bankole, A., \& Darroch, J. E. (2017). The Impact of Contraceptive Use and Abortion on Fertility in sub-Saharan Africa: Estimates for 2003-2014. Population and Development Review, 43(Suppl 1), 141-165.

Starbird E, Norton M, \& Marcus R. (2016). Investing in Family Planning: Key to Achieving the Sustainable Development Goals. Glob Health Sci Pract. 4(2),191-210. DOI:http://dx.doi. org/10.9745/GHSP-D-15-00374.

Stover, J., \& Ross, J. (2010). How Increased Contraceptive Use Has Reduced Maternal Mortality. Maternal and Child Health Journal, 14(5), 687-695.

Tan, P.C. \& Tey, N.P. (1994). Do Fertility Intentions Predict Subsequent Behavior? Evidence from Peninsular Malaysia. Studies in Family Planning, 25(4), 222-231.

Testa, M. R., \& Toulemon, L. (2006). Family Formation in France: Individual Preferences and Subsequent Outcomes. Vienna Yearbook of Population Research, 41-75.

United Nations, Department of Economic and Social Affairs, Population Division. (2015). World Population Prospects: The 2015 Revision, Key Findings and Advance Tables. Working Paper No. ESA/P/WP.241. Pp. 5

Willy, D. K., Muyanga, M. \& Jayne, T. (2019). Can Economic and Environmental Benefits Associated with Agricultural Intensification Be Sustained at High Population Densities? A Farm Level Empirical Analysis. Land Use Policy 81, $100-110$.

Wusu, O., \& Isiugo-Abanihe, U. C. (2019). Consistency of the Effects of Female Education on Fertility Across the North-South Demographic Divide in Nigeria, 2003-2013. Journal of Biosocial Science, 51(1), 138-153.

Yavinsky, R.W., Lamere, C., Patterson, K.P., Bremner, J. (2015). The Impact of Population, Health, and Environment Projects: A Synthesis of the Evidence. Working Paper. Washington (DC): Population Council, The Evidence Project. Retrieved January 20, 2019 from http:// evidenceproject.popcouncil.org/wp-content/ uploads/2015/06/PHE-Synthesis-Report1.pdf 